
aker's asthma is one of the most common forms of occupational asthma. The increasing knowledge in exposure-response relations accumulated in recent years is important in the understanding of baker's asthma. This development has made scientifically based prevention feasible today and baker's asthma should not be regarded as an inevitable occurrence any more.

In 1700 Bernardo Ramazzini described respiratory symptoms among bakers caused by exposure to flour dust. However, there are anecdotal references from antiquity describing how Roman slaves working in bakeries protected themselves by using cloth as a primitive respirator to cover their faces because their breathing suffered from inhaling flour.

\title{
CLINICAL PICTURE
}

Case reports from the beginning of the 20th century established the concept of baker's asthma as an allergic disease because of the observed combination of positive skin tests to flour extracts and respiratory symptoms suggestive of asthma. The aetiological role of sensitisation to flour in these cases was confirmed by bronchial challenge tests. Rhinitis is very common and usually precedes asthma. Conjunctivitis and skin symptoms may also occur. The baker is often atopic by skin or IgE tests. Symptoms develop after a latency period of months or years, even decades. Initially there is often a clear temporal relation between symptoms and periods of bakery work. Over time, respiratory symptoms may cease to resolve during time off from the bakery. Sensitisation to flour is traditionally often regarded as a prerequisite for the diagnosis of baker's asthma. Although the prognosis of baker's asthma is not reported in the literature, it is usually presumed that symptoms resolve if exposure to offending allergens is stopped.

\section{EPIDEMIOLOGY}

From the 1930s onward there was a number of cross sectional studies surveying populations of bakers, unfortunately many of them uncontrolled-that is, without comparing the bakers with controls. These studies varied considerably in the description of symptoms, and in the definitions of asthma and sensitisation. Also exposure to bakery dust varied across the studies. Although epidemiologically crude by today's standards, they showed that bakers have more lower respiratory tract symptoms, sometimes labelled as asthma and considered as "normal", but also nasal symptoms, indicating baker's rhinitis. ${ }^{1}$ Positive skin tests to flour were found not only among those with asthmatic symptoms but also among bakers with rhinitis or even among those without symptoms ("latent allergy"). The presence of flour allergy was usually included in the definition of Baker's asthma in the clinical setting. The earlier findings from the case series of an association between baker's asthma and atopy were corroborated in the cross sectional studies.

There are a few longitudinal studies estimating the incidence of respiratory symptoms and sensitisation to bakery allergens. Gadborg studied Danish bakers and published his results in 1956. He made a follow up of 487 out of 500 randomly selected bakers after 5-6 years. The incidence rate for sensitisation to flour was about 5.5 cases per 1000 person years, and for baker's asthma (symptoms and sensitisation) about 1.5. An often cited German study of bakers' apprentices by Herxheimer showed a cumulative incidence for sensitisation of $19 \%$ and $7 \%$ for respiratory symptoms after three years. As only one third of the original cohort were studied at that time point, the interpretation of the results is difficult. A Swedish retrospective study of trainee bakers showed male incidence rates for asthma of 3.0 cases per 1000 person-years (referents 0.9-1.9), and for rhinitis 29.4 cases per 1000 person-years (referents 10.1-11.1). ${ }^{23}$ A cohort of 300 newly employed UK bakers and millers was followed for a maximum of seven years. ${ }^{4}$ The incidence rates of work related chest symptoms was 41 per 1000 person-years, of work related eyes/nose symptoms 118 per 1000 person-years, of sensitisation to flour 22 per 1000 person-years, and of sensitisation to the enzyme fungal $\alpha$ amylase 25 per 1000 person-years. The incidence of work related chest symptoms and a positive skin prick test to flour or fungal $\alpha$ amylase was about 10 per 1000 person-years. 


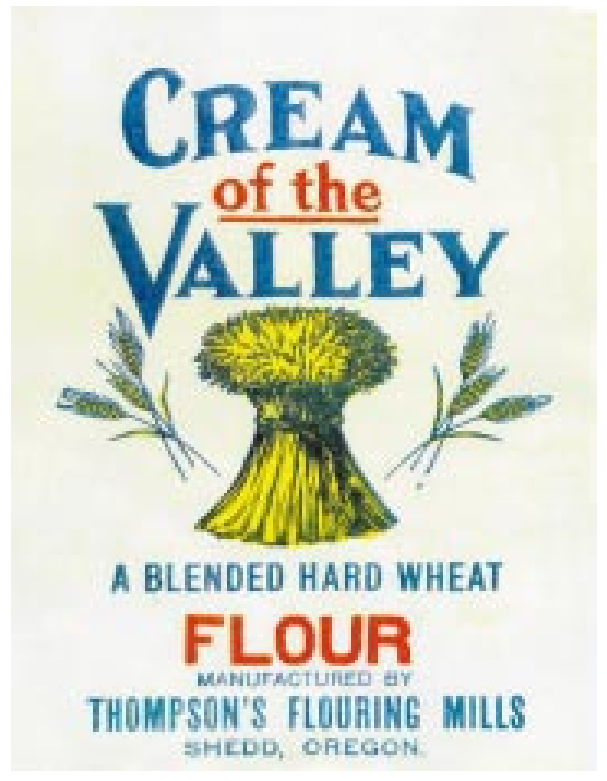

Register based studies

Baker's asthma is one of the most frequently reported forms of occupational asthma in several countries. The annual incidence in the UK was estimated to be $290-450$ cases per million according to the SWORD and SHIELD schemes during 1989 to 1994. The corresponding figure for Sweden was 800 in 1984-86 and for Finland 4000 in 1990. The differences between these figures can be accounted for by quite different reporting systems and possibly also differences in exposure. A small US asthma mortality study from Chicago, conducted from 1980 to 1988 and involving individuals aged 20-35 years, showed bakers to have almost nine times the age and race adjusted mortality rate of the city's general population. A British study found no increased respiratory mortality.

\section{ALLERGENS}

Another line of development in studies on baker's asthma was to explore what agents in flour and other components in bakery dust induced the formation of IgE antibodies. ${ }^{5}$

\section{Flours}

The specific IgE antibodies most often found in Baker's asthma or rhinitis are against cereal flours such as wheat, rye or barley (table 1). These species are taxonomically closely related and there is strong cross antigenicity between them. There are many flour proteins with allergenic capacity; as many as 40 were described in wheat, of which 20 crossreacted with rye.$^{67}$ Grass is also taxonomically related to cereals, and cosensitisation and cross reactivity between cereal flours and grass has been discussed in baker's asthma. Other, non-cereal flours such as soy and buckwheat were also reported as sensitisers in bakeries and related businesses.

\section{Enzymes}

Since the 1970s a variety of enzymes can be added to flour in order to enhance the baking process. Although enzymes are used in minute quantities (typically $\mathrm{mg} / \mathrm{kg}$ flour), they can cause sensitisation and baker's asthma (table 1). The most common enzyme is $\alpha$ amylase of fungal origin. ${ }^{8}$ The use of $\alpha$ amylase varies between countries and bakeries-in some enterprises the $\alpha$ amylase is routinely added to the flour, in others it is used for some products only, and in some it is not

Table 1 Allergens associated with baker's asthma
and rhinitis

used at all. The sensitisation rates for fungal $\alpha$ amylase vary across studies and depend on the amounts of amylase used in the different study populations.

\section{Other allergens}

A bakery is a complex environment with a multitude of potential sensitisers, and there are case reports of baker's asthma caused by moulds, yeast, eggs, sesame seeds, nuts, and insects, for example (table 1). The occurrence of sensitisation to these allergens is less well known than those cases caused by cereal flours or enzymes, and seems to be of marginal importance to the burden of disease in bakers. However, they should be kept in mind in the clinical setting if no sensitisation to common bakery allergens is found. Storage mites have been proposed as a bakery allergen but were refuted since sensitisation rates were similar among bakers and the general population.

\section{EXPOSURE}

Knowledge about the exposure to flour dust and other allergens in bakeries is of fundamental importance when analysing the risk for asthma. Inhalation of dust as well as allergens from wheat flour and $\alpha$ amylase has been measured and the exposure estimated. Bakers were grouped in task groups and factors affecting the variability in the exposure were studied. ${ }^{9}$ For the highest dust exposed task group it was shown that much of the flour dust exposure was caused by high peaks of short duration (minutes). This systematic approach provided much more detailed knowledge on the mean exposures and the variation in the different job tasks in bakeries. Together with individual information on health effects among the exposed bakers it proved to be a powerful tool for performing studies of exposure-response relations.

It was also found that a substantial proportion of flour dust particles had an aerodynamic diameter of $10 \mu \mathrm{m}$ or more. The respirable fraction amounted to about $10 \%$ and the thoracic fraction about $40 \%$ of the total particle mass. 


\begin{tabular}{|c|c|c|c|c|c|c|c|}
\hline \multirow[b]{2}{*}{$\mathrm{n}$} & \multicolumn{2}{|c|}{ Symptoms (\%) } & \multicolumn{2}{|c|}{ Pos SPT or RAST } & \multirow[b]{2}{*}{$\mathrm{n}$} & \multicolumn{2}{|c|}{ Dust from personal samples } \\
\hline & Eyes/nose & Chest & Flour & Any & & $\mathrm{GM}$ range $\left(\mathrm{mg} / \mathrm{m}^{3}\right)$ & Reference \\
\hline 133 & $0^{*}$ & & NR & NR & 133 & $0.2-1.8$ & Hartmann 1986 \\
\hline 139 & $11^{*}$ & & NR & NR & 139 & $1.0-4.4$ & \\
\hline 42 & $17^{*}$ & & NR & NR & 42 & $3.2-19.8$ & \\
\hline 183 & 13 & 9 & 5 & 28 & 32 & $0.01-3.0$ & Musk 1989 \\
\hline 96 & 30 & 17 & 5 & 35 & 47 & $1.7-11.0$ & \\
\hline 104 & 11 & 5 & 2 & 17 & 205 & $<1$ & Cullinan, Nieuwenhuijsen 1994 \\
\hline 90 & 15 & 3 & 6 & 25 & 191 & $1-5$ & \\
\hline 62 & 31 & 11 & 5 & 30 & 99 & $>5$ & \\
\hline 117 & $15^{*}$ & & 4 & NR & 151 & 0.5 (mean) & Houba 1998 \\
\hline 107 & $23^{*}$ & & 8 & NR & 120 & 0.8 (mean) & \\
\hline 122 & $29 *$ & & 14 & NR & 178 & 2.4 (mean) & \\
\hline
\end{tabular}

*Work related symptoms from the eyes or nose and chest.

GM, geometric mean; NR, not reported.

\section{EXPOSURE-RESPONSE RELATIONS}

There are at least four published exposure-response relation studies performed in cross sectional data from Switzerland, the UK, and the Netherlands (table 2). They all showed positive exposure-response relations-that is, higher prevalence of chest and/or nasal symptoms by higher exposure to bakery dust. There were also positive exposure-response relations for sensitisation to flour, usually wheat.

Two cross sectional studies from the Netherlands and the UK showed positive exposure-response relations for the rate of sensitisation to fungal $\alpha$ amylase by exposure to that enzyme.

Those rather remarkably consistent results in cross sectional materials were recently corroborated by two longitudinal studies from Sweden and the UK. ${ }^{40}$ The Swedish data showed significant associations between the dust concentrations at onset of disease and the risk for asthma or rhinitis. The risk of asthma was increased at mean dust concentrations of $3 \mathrm{mg} / \mathrm{m}^{3}$, whereas the risk for rhinitis was increased at mean dust concentrations of $1 \mathrm{mg} / \mathrm{m}^{3}$, indicating an increased risk in all bakery work tasks. The British study is of case referent design, with the lowest exposed bakers (mean dust concentration $0.8 \mathrm{mg} / \mathrm{m}^{3}$ ) as reference. The bakers in the second exposure category (mean dust concentration $1.2 \mathrm{mg} / \mathrm{m}^{3}$ ) had increased-but not significantly so-risks for work related chest or eyes/nose symptoms, or sensitisation to flour or $\alpha$ amylase. The confidence intervals were of considerable width. In the highest exposure category (mean dust concentration $4.4 \mathrm{mg} / \mathrm{m}^{3}$ ) there were significantly increased risks for all outcomes (chest or eyes/nose symptoms, or sensitisation). Analyses with flour allergen exposure instead of inhalable dust gave very similar results.

\section{WHAT DO WE WANT TO PREVENT?}

Primarily we want to prevent baker's asthma. The definition of baker's asthma might have been fairly simple to the clinician some years ago: a baker with a history suggesting asthma and sensitisation by allergy tests to one or several cereal flours. However, developments in epidemiology and allergy have made this definition of baker's asthma questionable in the context of prevention as well as in clinical practice. Surveys of bakers have shown work related respiratory symptoms to occur without a demonstrable sensitisation to flour or $\alpha$ amylase. Cullinan et al did not find any sensitisation among nine bakers with lower respiratory tract symptoms of new onset. ${ }^{11}$ Houba et al reported only 30\% of bakers with work related symptoms to be sensitised. ${ }^{12}$ This might be explained by sensitisation to other, as yet unknown bakery allergens, but another explanation is non-specific mucosal irritation caused by dust. The "latent allergy" phenomenon, where bakers become sensitised but without respiratory symptoms, also blurs the picture. There is little information in the literature on latent allergy, but it is indicated in the older studies where positive skin tests sometimes disappeared on follow up. On the other hand, sensitisation to flour or $\alpha$ amylase was a significant predictor (odds ratio 4.3) for work related symptoms in a longitudinal Italian study. ${ }^{13}$ The severity and duration of baker's asthma may very well differ according to whether or not there is demonstrable sensitisation to bakery allergens, but this does not seem to have been studied.

Furthermore, one could argue it would be beneficial to prevent baker's rhinitis since it often precedes asthma, although the predictive value is not reported in the literature. Rhinitis itself also impairs quality of life.

\section{PREVENTION BY MEDICAL SURVEILLANCE}

The goal of medical surveillance is secondary prevention by early detection of a disease process before the occurrence of clinically adverse health outcomes. Although sometimes recommended, there is little scientific evidence of the effectiveness of medical surveillance programmes targeting occupational asthma. There is one study by Gordon et al which indicated that a questionnaire for detecting baker's asthma was not sensitive enough and detected only half the number of cases. Other possible tools for surveillance are lung function and allergy tests. Spirometry is an insensitive test for asthma. Serial monitoring of peak expiratory flow rate, repeated tests of non-specific bronchial reactivity or allergy tests are perhaps more sensitive surveillance methods, but are labour intensive when applied in bakery work forces. In the absence of scientific data supporting its preventive potential, it seems questionable to allocate resources to costly medical surveillance if it would endanger implementing primary prevention by reducing exposure.

\section{PREVENTION BY MAXIMAL EXPOSURE LIMITS}

Reduction of exposure to factors associated with a disease does not necessarily mean reduction of the risk for the disease. 
Interventional studies are needed to test such hypotheses. However, exposure-response relations have been regarded as sufficient circumstantial support for reducing occupational exposures. Traditionally, bakery dust was often regarded as general or organic nuisance dust with standards set at concentrations of $5-10 \mathrm{mg} / \mathrm{m}^{3}$. The reported exposureresponse relations have initiated risk assessments in several countries: in the USA the American Conference of Governmental Industrial Hygienists adopted a threshold limit value (TLV) of $0.5 \mathrm{mg} / \mathrm{m}^{3}$, the Dutch expert committee has proposed a limit of $0.5 \mathrm{mg} / \mathrm{m}^{3}$, since January 2001 Sweden has set a limit of $3.0 \mathrm{mg} / \mathrm{m}^{3}$, and Germany is presently revising its $4.0 \mathrm{mg} / \mathrm{m}^{3}$ MAK (Maximale Arbeitsplatzkoncentration) value. These maximal exposure limits (MELs) are eight hour time weighted averages of inhalable dust by personal sampling.

The risk assessment for an MEL for dust is somewhat restricted by the grouping strategies and analytical methods used in the studies. For example, some studies compare "high" exposed groups with "low" exposed, but not with nonexposed. Heederik and Houba applied generalised additive modelling and smoothed plots of individual data in order to look for a possible exposure-response threshold for sensitisation to wheat. ${ }^{14}$ They concluded that there was no threshold and that sensitisation could occur at flour dust concentrations of $0.5-1.0 \mathrm{mg} / \mathrm{m}^{3}$.

Published exposure-response studies do not allow the identification of a NOAEL (no observable adverse effect level) for flour dust. Exposure to $3-6 \mathrm{mg} / \mathrm{m}^{3}$ of inhalable dust increases the risk for respiratory tract symptoms (including asthma and rhinitis) and sensitisation to flour several fold. The risk estimates for symptoms at exposures $<3 \mathrm{mg} / \mathrm{m}^{3}$ are sparse and of low precision because of the restrictions mentioned above. However, studies that have examined the effects of exposures $<3 \mathrm{mg} / \mathrm{m}^{3}$ indicate increased risks-for example, the Dutch studies showed sensitisation at low levels, and the Swedish study demonstrated increased risk for rhinitis at $1 \mathrm{mg} / \mathrm{m}^{3}$. Together with some safety margin, this indicates that an MEL should be in the range $0.5-1.0 \mathrm{mg} / \mathrm{m}^{3}$ in order to prevent a substantial fraction of asthma, rhinitis, and sensitisation to flour.

So far MELs are expressed as dust. Dust in bakeries normally consists of flour to about $90 \%$. Certain operations during confectionary work may emit dust with a high content of sugar, but this is usually evident from the task being performed. Consideration might be given to introducing an MEL based on the air concentration of flour allergen as a complement or instead of flour dust. The main argument against this approach is that most respiratory symptoms in bakers seem not to be related to flour sensitisation. Further obstacles are the diversity of allergens present in flour, without any single major allergen being identified, and the need for standardisation of the analyses. An MEL for fungal $\alpha$ amylase can also be considered since a standard for flour dust does not necessarily protect against sensitisation to $\alpha$ amylase. This has been highlighted by some measurements of high air concentrations of $\alpha$ amylase while dust levels were low. The risk assessment and management for $\alpha$ amylase may be different from that for flour. Progress in standardisation of the analytical process of $\alpha$ amylase was recently reported. ${ }^{15}$

\section{DUST CONTROL}

The key elements for dust control in bakeries are adequate local exhaust ventilation and good work practice. General dilution ventilation has only marginal effect on dust levels.

\section{Baker's asthma: key points}

Clinical

- Baker's asthma is often preceded by rhinitis, and skin symptoms are often concomitant

- Frequently there is atopy and sensitisation to flour and/or enzyme (for example, $\alpha$ amylase)

- Mechanisms behind cases without overt allergy to bakery allergens are unknown

- Risk is increased by high exposure to bakery dust

Management

- Reduce exposure by dust control or relocation

- Change of job to non-bakery work is often necessary

- Long term use of respirators is usually not feasible in bakeries

Prevention

- There is an exposure-response relation, meaning increased risks for baker's asthma, rhinitis, and sensitisation by exposure to flour or enzyme

- Today's MELs for flour dust $\left(=3 \mathrm{mg} / \mathrm{m}^{3}\right)$ probably do not protect against baker's asthma

- Dust control in bakeries includes adequate local exhaust ventilation and good work practice. General dilution ventilation has only marginal effect on dust levels.

Local ventilation should be concentrated to flour release points such as weighing stations, dough making machines, dough brakes, and bread machines. Such ventilation can most probably reduce dust exposure to concentrations below $1 \mathrm{mg} / \mathrm{m}^{3}{ }^{3}{ }^{16}$ Work practice to avoid flour dust becoming airborne includes careful bag emptying and empty bag handling, and vacuum cleaning instead of using pressurised air. The introduction of new work practice requires that bakers are given training. An example is a training programme implemented in Switzerland. In order to minimise the need for throwing flour to prevent the dough sticking to work surfaces, technical changes such as using divider oils and flow tables must also can be considered.

\section{MANAGEMENT}

As in other forms of allergic asthma, the management of choice for the classic type of baker's asthma with sensitisation is allergen avoidance. This can be achieved by technical dust control, relocation of the baker to a less exposed job task, or by having the baker wear respiratory protection. Because of the abundance of dust in most bakeries in relation to the minute allergen exposure needed to elicit symptoms in sensitised workers, change of employment is often necessary. Symptomatic bakers without sensitisation can be helped by relocation to less exposed tasks if symptoms are caused by non-specific irritation. Respirators are in my experience seldom well tolerated by bakers because of the heat in bakeries and the hindering of physical activity. They also cause discomfort when worn for long periods.

Immunotherapy with flour has been reported to be successful in baker's asthma but needs further evaluation.

Management includes bakers seeking medical care because of symptoms but also the identification of at risk workers through surveys of bakers performed by occupational health services. In such surveys it is important to handle the outcome for the individual baker in a structured and, as far as possible, scientifically justified way. A Scandinavian workshop on the prevention of bakers' occupational diseases addressed these two aspects of management and the following recommendations were expressed. 
- Asthmatics sensitised to flour or fungal $\alpha$ amylase should change to non-bakery employment

- Asthmatics without sensitisation to flour or fungal $\alpha$ amylase should be relocated to less exposed bakery tasks

- Bakers with rhinitis and sensitisation should be investigated closely and relocation to less exposed tasks should be considered

- Bakers sensitised to flour or fungal $\alpha$ amylase but without respiratory symptoms should be re-examined annually

- Bakers with rhinitis only but without sensitisation to bakery allergens do not warrant re-examination unless symptoms worsen.

\section{ACKNOWLEDGEMENTS}

I would like to thank Linnéa Lillienberg and Bengt Järvholm for comments on an earlier draft. The views expressed are entirely my own.

\section{REFERENCES}

1 Houba R, Doekes G, Heederick DJJ. Occupational respiratory allergy in bakery workers: a review of the literature. Am J Ind Med 1998;34:529-46.

- Good review of the literature up to 1998, especially the epidemiology.

2 Brisman J, Järvholm B. Occurrence of self-reported asthma among Swedish bakers. Scand J Work Environ Health 1995;21:487-93.

3 Brisman J, Järvholm B. Bakery work, atopy and the incidence of self-reported hay fever and rhinitis. Eur Respir J 1999;13:502-7.

4 Cullinan P, Cook A, Nieuwenhuijsen M, et al. Allergen and dust exposure as determinants of work-related symptoms and sensitization in a cohort of flour-exposed workers; a case-control analysis. Ann Occup Hyg 2001;45:97-103

5 Heederik D, Newman Taylor AJ. Occupational asthma in the baking industry. In: Bernstein IL, Chan-Yeung M, Malo J-L, Bernstein DI, eds. Asthma in the workplace. New York: Marcel Dekker 1999:377-97.

- Up to date review, with especially valuable sections on immunology and dust control.

6 Blands J, Diamant B, Kallós-Deffner L, et al. Flour allergy in bakers: identification of allergenic fractions in flour and comparison of diagnostic methods. Int Arch Allergy Appl Immunol 1976;52:392-406.

7 Sutton R, Skerritt JH, Baldo BA, et al. The diversity of allergens involved in baker's asthma. Clin Allergy 1984;14:93-107.

8 Baur X, Fruhmann G, Haug G, et al. Role of Aspergillus amylase in bakers's asthma [letter]. Lancet 1986;i:43.

9 Houba R, Heederik D, Kromhout H. Grouping strategies for exposure to inhalable dust, wheat allergens and $\alpha$-amylase allergens in bakeries. Ann Occup Hyg 1997;41:287-96.

- Presents the background and results of an exposure grouping technique in bakeries.

10 Brisman J, Järvholm B, Lillienberg L. Exposure-response relations for self reported asthma and rhinitis in bakers. Occup Environ Med 2000;57:335-40.

- Discussion on exposure-response relations for baker's asthma and rhinitis.

11 Cullinan P, Lowson D, Nieuwenhuijsen M, et al. Workrelated symptoms, sensitisation, and estimated exposure in workers not previously exposed to flour. Occup Environ Med 1994;51:579-83

12 Houba $\mathbf{R}$, Heederik D, Doekes G. Wheat sensitization and work-related symptoms in the baking industry are preventable. An epidemiologic study. Am J Respir Crit Care Med 1998;158:1499-503.

13 De Zotti R, Bovenzi M. Prospective study of work related respiratory symptoms in trainee bakers. Occup Environ Med 2000;57:58-61.

14 Heederik D, Houba R. An explanatory quantitative risk assessment for high molecular weight sensitizers: wheat flour. Ann Occup Hyg 2001; 45:175-85.

- Introduces risk assessment by general additive models in individual data.
15 Lillienberg L, Baur X, Doekes $G$, et al. Comparison of four methods to assess fungal $\alpha$-amylase in flour dust. Ann Occup Hyg 2000;44:421-33.

16 Heinonen K, Kulmala I, Säämänen A. Local ventilation for powder handling - combination of local supply and exhaust air. Am Ind Hyg Assoc J 1996:57:356-64.

- Laboratory measurements and simulations on how to reduce flour dust exposure.

\section{QUESTIONS (SEE ANSWERS ON P 426)}

(1) Which of the following statements on the present knowledge on exposure-response relations for baker's asthma is true?

(a) exposure-response relations for baker's asthma has not been studied

(b) there are no consistent results

(c) the risk for baker's asthma increases only at exposures to flour dust $>10 \mathrm{mg} / \mathrm{m}^{3}$

(d) the risk for baker's asthma starts to increase at exposures to flour dust $>3 \mathrm{mg} / \mathrm{m}^{3}$

(e) The risk for baker's asthma increases at exposures to flour dust $<0.5 \mathrm{mg} / \mathrm{m}^{3}$.

(2) What is the proposed management of a case of baker's asthma with allergy to flour?

(a) re-examination annually

(b) more close investigation

(c) no action

(d) job change to non-bakery work

(e) long term use of respiratory protection

(3) Which of the following statements on allergens associated with baker's asthma is false?

(a) enzymes are powerful allergens

(b) storage mite allergy is a common cause of baker's asthma

(c) allergens in cereal flours and grasses are closely related

(d) not all bakers with sensitisation to flour have baker's asthma

(e) atopy increases the risk for sensitisation to flour

(4) Important factors for successful dust control in a bakery are:

(a) general ventilation

(b) local exhaust ventilation

(c) cleaning by using vacuum cleaning instead of pressurised air

(d) implementing a training programme in good work practice

(e) alternate techniques (such as divider oils) instead of throwing flour to prevent dough sticking

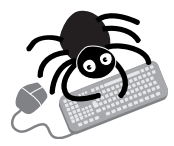

Additional references appear on the Occupational and Environmental Medicine website [www.occenvmed.com] 